\title{
Editorial
}

\section{La política social \\ y la participación ciudadana}

Los objetivos y alcances del conjunto de las políticas sociales están en relación directa con las causas y los efectos estructurales que genera el sistema económico y que socialmente se tipifican a partir de la desigualdad social, concretamente, a partir de las formas socioculturales y económicas que adquieren la marginación y la exclusión social.

Centroamérica, y en lo particular El Salvador, está experimentado nuevos enfoques en relación con la "Política Social". Tras lograr - a través de las negociaciones políticas - los acuerdos de paz, han venido desarrollándose nuevos escenarios y nuevos actores en relación cone el abordaje del conjunto de demandas sociales y económicas de los grupos más vulnerables del país y de la región. Esta inclusión de nuevos escenarios y actores ha propiciado centrífugamente la extensión de las políticas públicas tradicionalmente asociadas al gobiemo nacional y local, y ha garantizado en cantidad y calidad la obtención de mejores resultados gracias a las innovadoras formas de planificación, gestión y ejecución de proyectos. Esta nueva realidad se debe a que las políticas públicas han venido cobrando un mayor significado social, debido a la participación ciudadana expresada y organizada en lo que varios autores han denominado la "sociedad civil".

A diferencia de las décadas pasadas, donde el enfoque de las políticas públicas estaba dominantemente asociado a prácticas estatales de corte asistencialista y a fines utilitaristas, en la actualidad, los nuevos enfoques teórico-metodológicos tienden a enfocar la "política social" hacia la consecución sostenible de "bienes- 
tar social", entendiéndose por éste no sólo la extensión de coberturas en el campo de la salud, la educación, el trabajo, la vivienda, etc., sino, fundamentalmente, la oportunidad de construir entre los agentes que intervienen vínculos sociales, donde la población beneficiada y específicamente la más pobre (marginada y excluida), el gobiemo nacional y local, los organismos no gubernamentales y los organismos internacionales de cooperación técnica y finançiera puedan, de acuerdo con sus roles y posición específica, participar de manera efectiva en los procesos de diagnóstico, diseño, implementación, evaluación y seguimiento de las mismas.

Las políticas sociales —desde estos nuevos enfoques - se interesan por garantizar que los diferentes proyectos de desarrollo económico y social contengan criterios de cantidad y calidad, que coadyuven -más allá de las intenciones paliativas y compensatorias - a establecer una relación de complementariedad con otros aspectos fundamentales de la realidad social, tales como el mercado, el trabajo, la equidad de género, la participación ciudadana, entre otros. En este sentido y bajo esta nueva modalidad, las políticas sociales proporcionan nuevos significados a los escenarios políticos, económicos, culturales y sociales en tanto que al convertirse en un instrumento público, abre espacios para la consecución de los derechos sociales, garantizando que la ciudadanía ejercite con mayor plenitud los derechos civiles y políticos que por derecho le corresponde. Por otra parte, impulsa la modernización del Estado, haciéndolo más eficiente en cuanto impulsor del desarrollo humano y garante de los derechos fundamentales de todos y cada uno de los ciudadanos.

Sin embargo, el reconocimiento y la aceptación de este fin último de la "política social" implica asumir varios compromisos institucionales, tanto de carácter científico, social como político. Sin estos compromisos, los alcances de la política social serán limitados y cuestionables. Sin el aporte multidisciplinar del conocimiento científico difícilmente se podrá superar el carácter asistencialista que tradicionalmente ha sustentado la implementación de la política pública. Reaccionar institucionalmente sólo por los efectos nocivos o por las distorsiones del modelo económico y relativizar las causas subyacentes, es reducir de antemano la política social a su dimensión paliativa y corto placista, con la agravante de que al no enfrentar la espiral de la pobreza, en el mediano plazo, los recursos humanos, materiales y financieros no serán suficientes para enfrentar, en el futuro, la complejidad de estos efectos.

El diseño y la ejecución de las políticas sociales demandan un diagnóstico de las necesidades a las que pretende satisfacer. Este diagnóstico debe construirse con los aportes del conocimiento científico social y sus resultados deben ser considerados seriamente a la hora de promulgar leyes y desarrollar estas políticas sociales. De lo contrario, los alcances del "bienestar social" quedarían circunscritos a enfrentar los efectos nocivos de las políticas económicas, sin atacar $\longrightarrow$ por lo menos minimizar- las causas estructurales que lo generan. Unas 
políticas sociales de esta naturaleza quedarían truncadas ante la imposibilidad de transformar las estructuras económicas, sociales, políticas y culturales, precisamente porque es en estas estructuras donde se produce la desigualdad social.

En el ámbito social, interesa destacar la importancia que tiene la participación social en todo el proceso de las políticas sociales. La experiencia de la implementación de otros modelos nos enseña que para nada sirve tener un buen planteamiento técnico de estas políticas, si no toman en cuenta los factores socioculturales que obstaculizan o benefician sus alcances. El soporte humano circunscrito a contextos específicos es un tema que, en materia de políticas sociales, no se puede y no se debe obviar.

Es importante tomar en cuenta que la exclusión social genera patrones de conducta social de gran complejidad y que estas afectan las redes de relaciones sociales, la cohesión y la unidad social. La exclusión social recurrente en el tiempo genera diversos y contradictorios patrones de conducta social, que afectan la dinámica de trabajo y el seguimiento de una determinada política social. Así, por ejemplo, una actitud utilitarista o de resistencia y desconfianza hacia las entidades responsables de estos procesos de desarrollo, determinarán efectivamente los alcances de los objetivos y las metas de las políticas sociales.

Minimizar los condicionantes negativos y maximizar los condicionantes positivos es un aspecto que debe, entonces, considerarse fundamental en todo el proceso de diseño, ejecución, evaluación y seguimiento de la política social. Uno de los factores metodológicos para solventar estos problemas es la participación ciudadana. Sin embargo, en este campo es importante no partir de conceptos y modelos preconcebidos de participación. Por el contrario, en la elaboración del diagnóstico situacional se deben describir los planteamientos y mecanismos de participación con los que cuentan estos grupos y asumirlos como punto de partida.

Ciertamente, alrededor del tema de la participación ciudadana se encuentra un problema actitudinal. Sus nexos culturales dominantes siguen estando bajo la sombra del paternalismo y el asistencialismo. El ámbito de las políticas sociales puede contribuir al cambio actitudinal, creando las condiciones para un ejercicio saludable de participación entre los agentes involucrados. Por lo tanto, en la medida en que se propicie y estimulen los espacios de debate e intercambio y se reconozcan los aportes de cada una de las partes, se garantizará que entre estos agentes se establezcan relaciones homólogas. Sin este tipo de relación difícilmente se podrá transformar el problema actitudinal de cara a la participación ciudadana.

Modificar las actitudes hacia la participación implica, desde el punto de vista sociojurídico, reconocer y promover el ejercicio de los derechos fundamentales que nos asisten como personas, en cumplimiento de la Declaración Universal de los Derechos Humanos y de la Declaración Americana de los Derechos y Deberes del Hombre. En este sentido, cuando se afirma que "... todo individuo tiene derecho 
a la libertad de opinión y expresión...”, se está garantizando en torno al derecho de opinar, el derecho a recibir y difundir información en cualquier materia.

En El Salvador, y básicamente por parte del gobiemo, impera el discurso a favor de los derechos humanos; no obstante, está práctica puede crear la sensación de que más allá de la praxis, el discurso es suficiente para modificar actitudes en las personas y las entidades sociales. Obviamente esto no es cierto. Sin el establecimiento de mecanismos que garanticen social y jurídicamente la participación ciudadana y sin la institucionalización de espacios para opinar, discutir, imaginar soluciones descartando e incorporando elementos de análisis, difícilmente superaremos las actitudes paternalistas y asistencialistas que obstruyen el objetivo más genuino de las políticas sociales: construir participativamente el desarrollo humano superando causas y efectos estructurales del modelo económico y social vigente en el país.

En relación con el componente político, el tema de la voluntad política es un tema recurrente en cuanto a las políticas sociales se refiere. La creación de marcos legales y jurídicos para garantizar el éxito de las mismas depende, en gran medida, de lo que a nivel político realicen el gobierno nacional y local, respectivamente. En este sentido, uno de las primeros compromisos es enmarcar el rol del Estado en el sentido de definir sus responsabilidades y compromisos. El Estado no puede desatenderse y aislarse de las iniciativas que desarrollan diversas entidades de la sociedad civil.

Las políticas sociales deben enmarcarse dentro de una estrategia nacional y local de desarrollo humano y deben responder a las metas que ésta tenga en el corto, mediano y largo plazo. Por lo tanto, una responsabilidad inmediata e impostergable del Estado es definir un plan de nación con sus correspondientes estrategias, en los diversos campos socioeconómicos y políticos. Esto evitaría el inmediatismo y la improvisación con la que generalmente se asumen las crecientes demandas de la población, especialmente aquella que está sujeta a la pobreza y exclusión social. Evitaría, también, el oportunismo partidista de los partidos que son los responsables de la gestión pública. Utilizar las políticas sociales para fines propagandísticos partidistas es un acto inmoral e injusto. Implica llevarse el crédito de los logros obtenidos a costa de desconocer los aportes específicos de los otros agentes intervinientes. Proceder de esta manera no sólo conlleva un abuso de poder, sino que deteriora, a nivel actitudinal, los necesarios vínculos de confianza y credibilidad entre las partes involucradas.

El Salvador cuenta con buenas oportunidades para capitalizar las experiencias en tomo al ámbito de las políticas sociales. La adecuada articulación de estas con la participación ciudadana, redundará en términos de eficiencia, eficacia y sostenibilidad a ir resolviendo estructuralmente las situaciones de pobreza y marginación social que aquejan a la mayoría de nuestra población. Es decir, contribuirá a generar mayores niveles de desarrollo humano. 